\title{
Adjuvant Therapy in High-Risk Cutaneous Squamous Cell Carcinoma: New Challenges
}

\author{
GV Schiappacasse ${ }^{123 *}$ \\ ${ }^{1}$ Chief Physician, Oncology Department, Clinical Hospital, Chile \\ ${ }^{2}$ Oncology Department, Bupa Reñaca Clinic, Chile \\ ${ }^{3}$ Oncology Department, Ciudad del Mar Clinic, Chile
}

*Corresponding author: GV Schiappacasse, Chief Physician, Oncology Department, Clinical Hospital, Chile

\begin{abstract}
Non-melanoma skin cancer is the most common tumor in the world; and cutaneous squamous cell carcinoma (cSCC) accounts for $20 \%$ of cases. It has a very good prognosis, except for the high-risk group. Studies of this group, despite its low frequency (5\%), are extremely important because the cancer has a high risk of relapse and development of locoregional and distant metastasis. And this is directly correlated with higher and significant mortality. Therefore, since there is limited data on current adjuvant therapies after surgery, or the therapies are not beneficial, we propose to investigate the benefit of anti-PD-1 and epidermal growth factor receptor (EGFR) inhibitors as adjuvant therapies in high-risk cSCC as supported by translational research and based on the available evidence.
\end{abstract}

Keywords: Cutaneous Squamous Cell Carcinoma; High-Risk; Adjuvant; Immunotherapy; EGFR Inhibitors

\section{Introduction}

Non-melanoma skin cancer is the most common cancer in the world, and cutaneous squamous cell carcinoma (cSCC) accounts for $20 \%$ of cases [1]. In the United States, a $14 \%$ increase in the prevalence of non-melanoma skin cancer was reported from 2.006 to 2.012 [2]. That said, overall survival in cSCC is over 90\%; however, there is a high-risk group with a greater than $5 \%$ chance of relapse or development of lymph node and/or distant metastasis [3]. Studies in this group are extremely important despite its low frequency $(5 \%)$, because it has a poor prognosis (3-year risk of disease-related death is $30 \%$ if the patient has at least one risk factor versus $100 \%$ survival if the patient has no risk factors) [1].

\section{Risk Factors}

\section{Clinical Characteristics}

a) Tumor size: in $\mathrm{CSCC}$, a diameter greater than $2 \mathrm{~cm}$ is an independent risk factor for developing metastasis, increasing this risk 1.000-fold in tumors larger than $2 \mathrm{~cm} \mathrm{[4].}$ b) Localization in high-risk zones: in cSCC head and neck tumors have the highest risk of developing metastasis, including in small tumors. This risk factor is independent of tumor size [3]. Thus, higher risk zones are the pinna and labial mucosa [5].

c) Immunosuppression is considered: the most significant risk factor [3]. cSCC occurs 65 to 100 times more often in patients who undergo organ transplantation than in the general population. The pathogenesis of post-transplantation cSCC involves infection with human papilloma virus and using calcineurin inhibitors and azathioprine immunosuppressants [6]. Furthermore, immunosuppressed patients have a more aggressive form and a higher probability of local and distant relapse [7]. Hematological diseases, such as chronic lymphocytic leukemia, have a higher tendency to be associated with high-risk cSCC [8].

d) Tumor resection with a positive margin: up to 50\% of cases with a positive margin will have local recurrence, which 
increases the risk of regional and distant lymph node metastasis [9].

e) Development in skin sites subject to chronic inflammation processes: cSCC situated in chronic cutaneous processes (scars, ulcers, burns, radiodermatitis) have a higher risk of developing metastasis. This is related to the decrease in E-cadherin, which promotes greater dermal invasion by atypical keratinocytes [10].

\section{Histological characteristics}

a) Breslow thickness of more than $2 \mathrm{~mm}$ : in 5 years of followup, a tumor thickness less than $2 \mathrm{~mm}$ has a metastasis rate of $0 \%$, between 2 and $6 \mathrm{~mm}$ it is $4 \%$, and over $6 \mathrm{~mm}$ it is $16 \%$ [11].

b) Clark level IV or higher: cSCC that invades the reticular dermis (level IV) or hypodermal tissue (level V) increases the risk of developing metastasis [3].

c) Poor tumor differentiation: high degree cSCC has a higher risk of aggressive behavior $[12,13]$.

d) Histological types: acantholytic cSCC is a risk factor [4]. Intercellular desmosome lysis and connection loss between keratinocytes promotes dermal infiltration with atypical keratinocytes. Desmoplastic cSCC has infiltrative growth, greater perineural invasion (PNI); and a significant risk of local or distant recurrence [14].

e) Perineural invasion (PNI) is uncommon in cSCC (2.5\% to $14 \%$ ) [15]. However, it is important because of its association with a higher risk of local and distant recurrence [16]. In addition, when thicker nerves (at least $0.1 \mathrm{~mm}$ ) are compromised, the prognosis is worse compared to PNI of thinner nerves [3].

\section{A Cohort Study using a Multivariable Analysis Confirmed the Following Independent Risk Factors for Lymph Node Metastasis and Disease-Related Death in Cscc}

1) Tumors greater than $2 \mathrm{~cm}$ in diameter

2) Poor differentiation

3) Deep infiltration (beyond the subcutaneous fat tissue)

4) Localization on the pinna

5) PNI is associated with a higher risk of disease-related death, as well as anogenital localization. (However, few studied cases presented anogenital localization, which decreases the statistical strength of this assertion).

6) Poor differentiation and deep infiltration are associated with worse overall survival [17]

State of the Art in High-Risk cSCC
Table 1: Risk factors in cSCC.

\begin{tabular}{|c|c|}
\hline \multicolumn{2}{|c|}{ 1) Clinical characteristics of high-risk cSCC } \\
\hline a) Size of the lesion & b) Location of the tumor \\
\hline c) Immunosuppression & d) Positive margins \\
\hline \multicolumn{2}{|c|}{ e) Site of chronic inflammation } \\
\hline \multicolumn{2}{|c|}{ 2) Histological characteristics of high-risk cSCC } \\
\hline a) Thickness (level of Breslow) & b) Depth (level of Clark) \\
\hline $\begin{array}{l}\text { c) Degree of tumor differentiation } \\
\text { (degrees of Broders) }\end{array}$ & d) Histological type \\
\hline \multicolumn{2}{|c|}{ e) Perineural invasion } \\
\hline Note: with a positive factor the & s classified as high-risk [3] \\
\hline
\end{tabular}

\section{State of the Art in High-Risk cSCC}

Primary surgery: Mohs micrographic surgery (MMS) is the treatment of choice. A $10 \mathrm{~mm}$ clear margin in low-risk cSCC is sought, and at least $15 \mathrm{~mm}$ in cSCC with more than one risk factor [18].

Lymphadenectomy: $80 \%$ of high-risk cSCC cases develop regional lymph node metastasis, regional lymphadenectomy is recommended. To reduced morbimortality from lymphadenectomy, the sentinel lymph node is checked. The evidence shows that sentinel node biopsies are positive more often in T2 lesions (more than $2 \mathrm{~cm}$ in diameter) and the test has excellent negative predictive values [18]. Since this evidence is retrospective, prospective studies are required to define the definitive role of sentinel node biopsy. Yet, in a retrospective preoperative study in squamous cell cancer of the head and neck, scanner, nuclear magnetic resonance, ultrasound, and PET-CT showed moderate/low sensitivity and high specificity with no significant differences between them. Combining imaging techniques improved sensitivity without losing specificity [19]. However, despite the high specificity shown by these diagnostic techniques, the lack of prospective evidence does not yet recommend using these tests to make decisions about whether to perform regional lymphadenectomy.

Radiation Therapy: used as an alternative to primary treatment in inoperable cases or if the surgery will cause significant deformities. Extrapolating from a study in cutaneous basal cell carcinoma, radiation therapy has a higher local failure rate and a lower cosmetic outcome than MMS [20]. Furthermore, it is contraindicated in tumors with bone invasion, lymph node metastasis, and previously irradiated recurrent tumors. It should also be avoided in genetic syndromes associated with increased radiosensitivity (xeroderma pigmentosum) and in active connective tissue diseases [21]. But as high-risk cSCC tends to progress and it is directly correlated with higher mortality, adjuvant strategies are needed to decrease this risk.Adjuvant Therapies 


\section{Adjuvant Therapies}

Radiation therapy: in high-risk cSCC, the risk of local recurrence is $20 \%$ to $50 \%$ with surgery alone. Therefore adjuvant radiation therapy is recommended if there are positive margins (and they cannot be surgically extended), with T4 disease, clinical PNI (with neurological manifestations), or there are two or more risk factors, lymphovascular invasion, and immunosuppression $[22,23]$.

In the case of PNI, adjuvant radiation therapy after MMS improves local control from $92 \%$ to $100 \%$ [15]. In microscopic PNI, adjuvant radiation therapy is recommended if there are variables which increase the risk of local recurrence:

1) Multifocal infiltration

2) Nerve diameter greater than $0.1 \mathrm{~mm}$

3) Infiltration of named nerves

4) Accompanying immunosuppression [23]. However, it should be made clear that the data on the efficacy of this adjuvant therapy are still limited [24].

Immunomodulators: in kidney transplant patients who have presented with more than 10 keratinocyte skin lesions, oral retinoids decrease the risk of developing new actinic keratosis (premalignant lesion) or cSCC lesions versus placebo [25]. Experts recommend them as chemoprevention for patients with a history of multiple actinic keratosis or cSCC lesions [18]. However, a phase 3 , prospective, randomized study on aggressive cSCC looked at adjuvant therapy with 13-cis-Retinoic plus alpha-interferon after surgery (with or without radiation therapy). There was no benefit on recurrence or the onset of new skin tumors versus the control group [26]. Given the high quality of the study and its results, we cannot routinely recommend this adjuvant therapy.

Chemotherapy: In a retrospective study, low-dose Capecitabine administered to treated cSCC patients with immunosuppression due to organ transplant decreased the risk of developing new cSCC and actinic keratosis [27]. However, there is no evidence that the routine use of adjuvant chemotherapy after surgery is beneficial [18]. As the known adjuvant therapies are based on limited evidence or do not provide any benefit, it becomes necessary to design new strategies.

\section{New Perspectives for Adjuvant Therapies in High- Risk cSCC}

\section{Re-establish Natural Immune Signals. This Perspective Is Based On The Following Evidence:}

a) Immunosuppression is an etiological risk factor in cSCC. Ultraviolet (UV) light produces an immunosuppressant effect. UVB radiation decreases the number of cells and the efficacy of antigen presentation in Langerhans skin cells and activates phospholipase A and lipoprotein-associated phospholipase production (which produces a local inflammatory effect). UVA radiation also has an immunosuppressant effect by activating lipoprotein-associated phospholipase and protein kinase C [28]. In addition, the incidence of cSCC is higher in organ transplant and stem cell recipients than in the general population $[6,29]$.

b) Immunosuppression is the most relevant risk factor in cSCC. Thus, in immunosuppressed patients, this tumor has more aggressive growth, a higher probability of local relapse, and a 5- to 10-fold higher risk of metastasis [3].

c) PD-1 is a T-lymphocyte membrane protein which binds with its membrane ligand PD-L1, expressed by the tumor cell, causing immune cell anergy. The use of monoclonal antibodies that release PD-1 from its union with PD-L1 leads to activation of T-lymphocytes and the immune cell anti-tumor response [30, 31]. The F.D.A. approved the use of Cemiplimab and Pembrolizumab (anti-PD-1 monoclonal antibodies) in metastatic and locally advanced cSCC, which is not a candidate for surgery or curative radiation therapy. Both have a high response rate, prolonged duration of response and acceptable toxicity similar to other antiPD1 drugs was reported [32, 33].

d) By damaging tumor DNA, radiation therapy increases the presentation of neoantigens which promote tumor infiltration by dendritic cells, macrophages, and cytotoxic CD8+ T-cells. This determines an immune response at non-irradiated sites (abscopal effect) [34]. A preclinical study showed a correlation between this effect and a biologically effective high dose [35]. Consequently, high-dose fractionation radiation therapy will have a greater immune effect than radiation therapy with classic fractionation [36]. Preclinical and clinical studies have demonstrated the immunotherapy potency of this effect when combined with radiation therapy [34, 37]. 
Table 2: Tumor response of Cemiplimab and Pembrulizumab in advanced cSCC.

\begin{tabular}{|c|c|c|c|}
\hline & Cemiplimab: Cohorts of the & Cemiplimab: & Pembrulizumab: \\
\cline { 3 - 4 } & Phase 1 Study (n=26) & $\begin{array}{c}\text { Cohorts of the Phase 2 Study } \\
\text { (n=59) }\end{array}$ & $\begin{array}{c}\text { Cohorts of the Phase 2 Study } \\
\text { (n=105) }\end{array}$ \\
\hline Objetive response & $50 \%$ & $47 \%$ & $34 \%$ \\
\hline Complete response & $0 \%$ & $7 \%$ & $4 \%$ \\
\hline Partial response & $50 \%$ & $41 \%$ & $31 \%$ \\
\hline Stable disease & $23 \%$ & $15 \%$ & - \\
\hline Progressive disease & $12 \%$ & $19 \%$ & - \\
\hline $\begin{array}{c}\text { Duration of response: six month or } \\
\text { longer }\end{array}$ & - & $57 \%$ & $69 \%$ \\
\hline
\end{tabular}

\section{Based on The Best Available Evidence, We Hypothesize That In High-Risk Cscc After MMS that}

Adjuvant hypofractionation radiation therapy (to increase the radiation dose per fraction and to potentiate the immune effect) together with Cemiplimab or Pembrolizumab and then Cemiplimab or Pembrolizumab as maintenance versus adjuvant radiation therapy with standard fractionation would decrease the risk of recurrence and locoregional and distant metastasis and improve overall survival.

\section{Use of Epidermal Growth Factor Receptor (EGFR) Inhibitors. This Perspective is Based on the Following Evidence}

a) EGFR is a transmembrane receptor protein, which, when binding to its ligand, dimerizes and activates the intracellular tyrosine kinase domain by autophosphorylation. This activates intracellular pathways which translates into increased cell proliferation, angiogenesis, invasion and metastasis, and inhibition of apoptosis [1]. EGFR has a high expression in normal skin keratinocytes and in many epithelial tumors, including cSCC $[38,39]$, which makes it a therapeutic target.

b) Cetuximab (chimeric monoclonal antibody which is a competitive EGFR inhibitor) and Gefitinib (tyrosine kinase inhibitor, the active site of EGFR) have been demonstrated to have a disease control rate over 50\% in unresectable cSCC and recurrent or metastatic squamous cell carcinoma of the head and neck, respectively [40, 41].

c) In advanced adenocarcinoma of the colon, KRAS and NRAS mutations independently decrease the survival benefit with Cetuximab [42]. However, in advanced cSCC, the incidence of 11 EGFR, RAS, and BRAF mutations is very low; therefore it is not necessary to measure them before starting Cetuximab [42]. We extrapolate the same behavior in localized high-risk cSCC.

d) A retrospective study on locally advanced cSCC (1 cohort) looked at the use of radiation therapy (12 to 80 Gy with a median dose of 60 Gy in 30 fractions) in combination with Cetuximab.
It described a $64 \%$ response rate with a median time to progression of 6.4 months and a median survival of 8 months. Toxicity with a grade greater than or equal to 3 occurred in $83 \%$ of participants. This high toxicity is explained because $75 \%$ of the cases presented moderate to severe comorbidity and $42 \%$ had immunosuppression [43]. This enables us to confirm the utility of Cetuximab as a radiosensitizer.

e) In a retrospective series in localized high-risk cSCC, Cetuximab (combined with surgery or radiation therapy) showed an overall response of $50 \%$ and median disease-free survival of 6.35 months [44].

\section{Based on the best available evidence, we hypothesize that in high-risk cSCC after MMS that}

Adjuvant radiation therapy together with EGFR inhibitor, and then EGFR inhibitor used as maintenance, versus adjuvant radiation therapy alone would decrease the risk of recurrence and locoregional and distant metastasis and would increase overall survival.

\section{What is the Optimal Duration of Adjuvant Therapy?}

In high-risk cSCC, the highest probability of locoregional and distant metastasis occurs in the first two years (70\% to 80\%) [45]. Therefore, we hypothesize 2 years of adjuvant therapy for both presented types of therapy.

\section{Conclusion}

High-risk cSCC has a high probability of progressing and lower survival, unlike cSCC with no risk factors. Therefore, it is important to investigate effective adjuvant therapies in this group which decrease relapses and improve survival. Since the evidence in this area is limited, based on translational medicine, we should apply laboratory discoveries about tumor biology (immune signal regulation and epidermal receptor expression) to the clinical field. Thus, phase 3,12 prospective, randomized trials are needed for adjuvant therapies in high-risk cSCC. We propose two lines of study which, in our opinion, have the best available evidence for beginning this research. 


\section{References}

1. Cranmer L, Engelhardt C, Morgan S (2010) Treatment of Unresectable and Metastatic Cutaneous Squamous Cell Carcinoma. The Oncologist 15(12): 1320-1328.

2. Rogers HW, Weinstock MA, Feldman SR, Coldiron BM (2012) Incidence Estimate of Nonmelanoma Skin Cancer (Keratinocyte Carcinomas) in the U.S. Population. JAMA Dermatol 51(10): 1081-1086.

3. Vasquez M, Garay I, Kurpis M, Monti FC, Ruiz Lascano A, et al. (2017) High-risk invasive cutaneous squamous cell carcinoma: use of current classification. Rev argent Dermatol 98(3).

4. Nuño A, Vicente F, Pinedo F, López JL (2012) High risk skin epidermoid carcinoma. Actas Dermosifiliogr 103(7): 567-578.

5. Edge SB, Byrd DR, Compton CC, Fritz AG, Greene FL, et al (2010) AJCC Cancer Staging Manual. Seventh edition. New York, NY: NYL Springer.

6. Chockalingam R, Downing C, Tyring SK (2015) Cutaneous Squamous Cell Carcinoma in Organ Transplant Recipients. J Clin Med 4(6): 1229-1239.

7. Euvrard S, Kanitakis J, Claudy A (2003) Skin cancers after organ transplantation N Engl J Med 348(17): 1681-1691.

8. Mehrany K, Weenig RH, Lee KK, Pittelkow MR, Otley CC, et al. (2005) Increased metastasis and mortality from cutaneous squamous cell carcinoma in patients with chronic lymphocytic leukemia. J Am Dermatol 53(6): 1067-1071.

9. Huang C, Boyce SM (2004) Surgical margins of excision for basall cell carcinoma and squamous cell carcinoma. Semin Cutan Med Surg 23(3): 167-173.

10. Lyakhovitsky A, Barzilai A, Fogel M, Trau H, Hussar M, et al. (2004) Expression of E-cadherin and beta catenin in cutaneous squamous cell carcinoma and its precursors. Am J Dermatopathol 26(5): 372-378.

11. Brantsch K, Meisner C, Schonfi B, Trilling B, Wehner-Caroli J, et al (2008) Analysis of risk factors determining prognosis of cutaneous squamouscell carcinoma: a prospective study. Lancet Oncol 9(8): 713-720.

12. Rowe DE, Carroll RJ, Day CD (1992) Prognostic factors for local recurrence, metastasis, and survival rates in squamous cell carcinoma of the skin, ear and lip. J Am Acad Dermatol 26(6): 976-990.

13. Cherpelis B, Marcusen C, Lang PG (2002) Prognostic factors for metastasic in squamous cell carcinoma of the skin. Dermatol Surg 28(3): 268-273.

14. Breuninger H, Schaumburg-Lever G, Holzschuh J, Horny HP (1997) Desmoplastic squamous cell carcinoma of skin and vermilion surface: a highly malignant subtype of skin cancer. Cancer 79(5): 915-919.

15. Han A, Ratner D (2007) what is the role of adjuvant radiotherapy in the treatment of cutaneous squamous cell carcinoma with perineural invasion? Cancer 109(6): 1053-1059.

16. Ross AS, Whalen FM, Elenitsas R, Xu X, Trovel AB, et al (2009) Diameter of involved nerves predicts outcomes in cutaneous squamous cell carcinoma with perineural invasion: an investigator-blinded retrospective cohort study. Dermatol Surg 35(12): 1859-1866.

17. Schmults CD, Karia PS, Carter JB, Han J, Qureshi AA, et al. (2013) Factors predictive of recurrence and death from cutaneous squamous cell carcinoma: a 10-years, single-institution cohort study. JAMA Dermatol 149(5): 541-447.

18. Parikh S, Patel V, Ratner D (2014) Advances in the management of cutaneous squamous cell carcinoma. F1000Prime Rep 6: p. 70.

19. Yoon DY, Hwang HS, Chang SK, Rho Y, Ahn HY, et al (2009) 18F-FDG PET/ CT, and their combined use for the assessment of cervical lymph node metastases in squamous cell carcinoma of the head and neck. Eur Radiol 19(3): 634-642.
20. Avril MF, Auperin A, Margulis A, A Gerbaulet, P Duvillard, et al. (1997) Basal cell carcinoma of the face: Surgery or radiotherapy? Result of a randomized study. Br J Cancer 76(1): 100-106.

21. Bichakjian CK, Olencki T, Aasi SZ (2016) Squamous cell skin cancer. NCCN Guidelines.

22. Jennings L, Schmults CD (2010) Management of high-risk squamous cell carcinoma cutaneous. J Clin Aesthet Dermatol 3(4): 39-48.

23. Manyam BV, Joshi N, Koyfman SA (2017) A review of the role of externalbeam radiation therapy in nonmelanomatous skin cancer. Appl Rad Oncol 6(2): 6-10.

24. Jambusaria-Pahlajani A, Hess SD, Katz KA, Berg D, Schmults CD, et al. (2010) Uncertainty in the perioperative management of high-risk cutaneous squamous cell carcinoma among Mohs surgeons. Arch Dermatol 146(11): 1225-1231.

25. Bavinck JN, Tieben LM, Van der Woude FJ, Tegzess AM, Hermans J, et al (1995) Prevention of skin cancer and reduction of keratotic skin lesions during acitretin therapy in renal transplant recipients: a double-blind, placebo-controlled study. J Clin Oncol 13(8): 1933-1938.

26. Brewster AM, Lee JJ, Gary L, Clayman JL, Clifford MJ, et al (2007) Randomized Trial of Adjuvant 13-cis-Retinoic Acid and interferon Alfa for Patients with Aggressive Skin Squamous Cell Carcinoma. J Clin Oncol 25(15): 1974-1978.

27. Jirakulaporn T, Endrizzi B, Lindgren B, Mathew J, Lee PK, et al (2011) Capecitabine for skin cancer prevention in solid organ transplant recipients. Clin Trasplant 25(4): 541-548.

28. Mercadillo P, Moreno LM (2013) Pathophysiology of squamous cell carcinoma. Dermatol rev Mex 57: 118-127.

29. Depry JL, Vyas R, Lazarus HM, Caimi PF, Gerstenblith MR, et al (2015) Cutaneous Malignant Neoplasms in Hematopoietic Cell Transplant Recipients: A Systematic Review. JAMA Dermatol 151(7): 775-782.

30. Dudley JC, Lin MT, Le DT, Eshleman JR (2016) Microsatellite instability as a biomarker for PD-1 blockade. Clin Cancer Res 22(4): 813-820.

31. Schiappacasse G, Schiappacasse E (2019) Is Adjuvant Chemotherapy Efficient in Colon Cancer with High Microsatellite Instability? A Look towards the Future. Cancer Res 79(3): 441-444.

32. Migden MR, Rischin D, Schmults CD, Guminski A, Hauschild A, et al (2018) PD-1 Blockade with Cemiplimab in Advanced Cutaneous Squamous-Cell Carcinoma. N Engl J Med 379(4): 341-351.

33. Grob JJ, Gonzalez R, Basset-Seguin N, Schachter J, Vornicova O, et al (2019) KEYNOTE-629: Phase 2 study of pembrolizumab for recurrent/ metastasic or locally advanced unresectable cutaneous squamous cell carcinoma (cSCC) . J Clin Oncol 37(15).

34. Asna N, Livoff A, Batash R, Debbi R, Schaffer P, et al. (2018) Radiation therapy and immunotherapy-a potencial combination in cancer treatment. Curr Oncol 25(5): e454-e460.

35. Marconi R, Strolin S, Bossi G, Stiragi L (2017) A meta-analysis of the abscopal effect in preclinical models: Is the biologically effective dose a relevant physical trigger?. Plos One 12(2): e0171559.

36. Deloch L, Derer A, Hartmann J, Frey B, Fietkau R, et al (2016) Modern Radiotherapy Concepts and the Impact of Radiation on Inmune Activation. Front Oncol 6: pp. 141.

37. Koo T, Kim IA (2016) Radiotherapy and immune checkpoint blockade: a snapshot in 2016. Radiant Oncol J 34(4): 250-259.

38. Maubec E, Duvillard P, Velasco V, Crickx B, Avril MF, et al. (2005) Immunohistochemical analysis of EGFR and HER-2 in patients squamous cell carcinoma of the skin. Anticancer Res 25(12B): 1205-1210.

39. Yanagi T, kitamura S, Hata $\mathrm{H}$ (2018) Novel therapeutic targets in cutaneous squamous cell carcinoma. Front Oncol 8: p. 79. 
40. Maubec E, Petrow P, Durvillard P, Laouenan C, Duval X, et al (2010) Cetuximab as first-line monotherapy in patients with skin unresectable squamous cell carcinoma: Final results of a phase II multicenter study. J Clin Oncol 28(15_suppl): 8510.

41. Cohen EE, Rosen F, Stadler WM, Recant W, Stenson K, et al (2003) Phase II trial of ZD1839 in recurrent or metastatic squamous cell carcinoma of the head and neck. J Clin Oncol 21(10): 1980-1987.

42. Picard A, Pedeutour F, Peyrade F, Saudes L, Duranton-Tanneur V, et a (2017) Association of Oncogenic Mutations in Patients With Advanced Cutaneous Squamous Cell Carcinoma Treated With Cetuximab. JAMA Dermatol. 153(4): 291-298.
43. Samstein RM, Ho AL, Lee NY, Barker CA (2014) Locally advanced and unresectable cutaneous squamous cell carcinoma: outcomes of concurrent cetuximab and radiotherapy. J Skin Cancer 2014: 284582.

44. Trodello C, Higgins S, Ahadiat O, Ragab O, In G, et al (2019) Cetuximab as a Component of Multimodality Treatment of High-Risk Cutaneous Squamous Cell Carcinoma: A Restrospective Analysis From a Single Tertiary Academic Medical Center. Dermatologic Surgery 45(2): 254267.

45. Rowe DE, Carroll RJ, Day CL (1992) Prognostic factors for local recurrence, metastasis, and survival rates in squamous cell carcinoma of the skin, ear, and lip. Implications for treatment modality selection. J Am Acad Dermatol 26(6): 976-990.

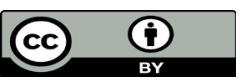

This work is licensed under Creative Commons Attribution 4.0 License

To Submit Your Article Click Here: Submit Article

DOI: 10.32474/OAJOM.2020.04.000179

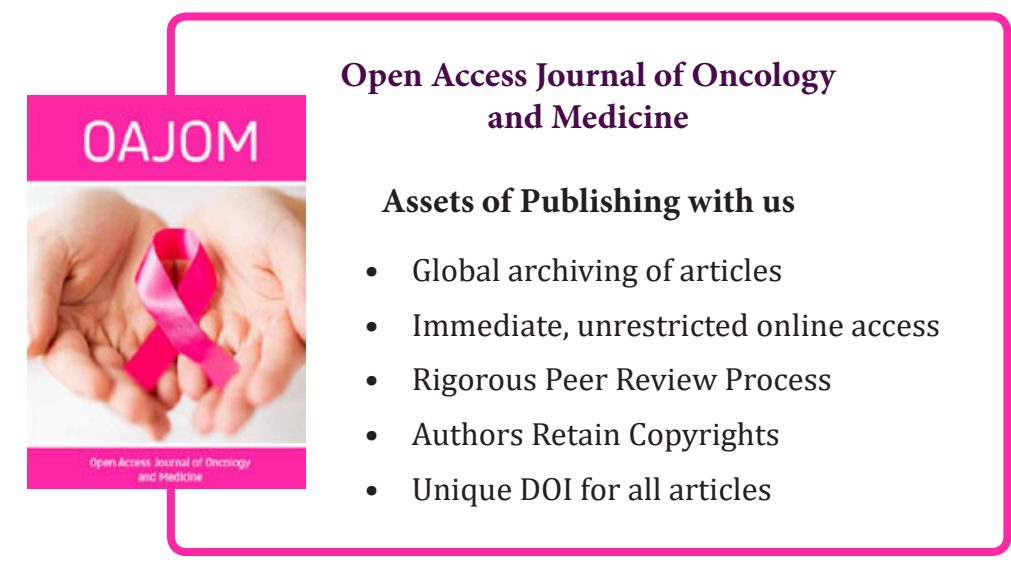

